\title{
A FLORA BRASILEIRA E OS NATURALISTAS E HORTICULTORES BELGAS NO SÉCULO XIX.
}

\author{
EDDY STOLS \\ da "Fondation Nationale de la Recherche Scientifique", \\ Bruxelas.
}

No âmbito da história geral das ciências, a botânica foi até agora focalizada de maneira bastante satisfatória e recebeu amplamente sua parte em comparação com outros setores desfavorecidos (1). Aparentemente, sua história parece uma das mais fáceis com documentação abundante e muito atrativa. Sem dúvida, aqui também, o inventário de problemas, incógnitas e projetos é impressionante: história das expedições botânicas, dos jardins botânicos, das plantas cultivadas... (2). Em face das pesquisas feitas e da massa de conhecimentos disponíveis, o historiador deve estranhar o diminuto aproveitamento mútuo e o pouco relacionamento entre a história da botânica e a história geral. Cada uma trabalha em recinto fechado ou se contenta com trivialidades (3). Pouco ou nada se estuda a botânica em sua influência sôbre a sociedade ou como expressão da mesma. Que confrontação reveladora, que diálogo apaixonante, entretanto, para a história econômica e social, para uma história das mentalidades! Mas confessemos ràpidamente nossas dívidas ao sugestivo livro de Fernand Braudel, Civilisation matérielle et capitalisme. De outro lado são o estudo das relações belgo-brasileiras e a ociosa e leiga

(1). - Histoire générale des sciences, editado por R. 'TATON, t. 2 e 3, Paris, 1958-1961; P. LAIN ENTRALGO, Panorama historique de la science moderne, Paris, 1967; M. GUIMARÃES FERRI, A botânica no Brasil, in As ciências no Brasil, editada por F. DE AZEVEDO, São Paulo, s.d., t. II, p. 149-200; História Geral da Civilização Brasileira, editada por S. BUARQUE DE HOLANDA, t. II, 1, p. 119-129;; C. DE MELLO LEITÃO, História das exepedições científias no Brasil, São Paulo, 1941.

(2). - F. VERDOORN, Problems of Botanical Historiography, in Archives internationales d'histoire des sciences, $\mathrm{XV}, 1951, \mathrm{p}$. 448-457.

(3). - G. TERGIT, Flowers through the Ages, Londres, 1961; L. GUYOT, Histoive des fleurs, in Que sais-je, Paris, 1961; H. G. BAKER, Plants and Civilization, Londres, 1964. 
contemplação de uns belos volumes ilustrados de botânica que nos levam a tentar uma aproximação neste assunto da flora brasileira e dos naturalistas e horticultores belgas no século XIX.

Foi com o renascimento, os descobrimentos e o capitalismo comercial que a botânica moderna encontrou seus primeiros grandes incentivos. Por certo, os Países-Baixos deviam ter um papel preponderante no seu desenvolvimento. Se espanhóis, portuguêses e franceses foram os primeiros a trazer da India e da América plantas desconhecidas, se na Itália se organizou o primeiro jardim botânico, os botânicos flamengos compensaram seu atraso pela descrição minuciosa, pela coleção sistemática e pelas primeiras tentativas de classificação. Ao lado de Rembertus Dodoenaeus, que teve seu Livro de ervas editado por Plantin, e de Mathias Lobel, que trabalhou para a côrte inglêsa, uma figura de destaque foi sem dúvida Charles de l'Escluse, aliás Clusius (* 1526 - †1609). Estudou êle em Montpellier, viajou com um Fugger pela Espanha e por Portugal, dirigiu os jardins de Maximiliano II em Viena e terminou sua carreira lecionando na nova Universidade de Leiden. Clusius não sòmente traduziu e editou em Antuérpia os trabalhos de Garcia da Orta, Acosta e Monardes, mas escreveu uma flora da Espanha e da Europa Central e, sobretudo, os Exoticorum libri decem e Rariorum plantarum historiae com vários apêndices (4). Estas duas últimas obras é que demonstraram, anos antes da invasão holandesa no Brasil e dos levartamentos botânicos de Marcgrave e Piso, particular interêsse pelas coisas brasileiras, fato geralmente desconhecida pela bibliografia brasileira (5). Nessas êle descreveu o jenipapo, o mamoeiro, o cajú, vários tipos de feijão e de mandioca, além de elemẹntos da fauna brasileira como papagaios, macacos, serpentes, aranhas, beija-flôres e uma preguiça (6). Clusius, que não saiu do continente europeu, não sòmente confiava nas descrições de Staden, Léry e Thevet, como também procurava suas próprias fontes de informação. Durante sua estadia em Lisboa, por volta de 1564, êle contactou na casa do comerciante Sebaldo Lins o filho dêste, Rodrigo, que, chegando de Pernambuco, trazia várias plantas, papagaios e macacos (7). Para Flandres êle levou pimenta do Brasil, que chegou a crescer no jardim de Charles de Saint-Omer, senhor de Moerkerke (8). Por tôda a Europa, especialmente em Londres,

(4). - F. W. HUNGER, Charles de l'Escluse, Leiden, 1927.

(5). F. C. HOEHNE, Botânica e Agricultura no Brasil (Século XVI), in Brasiliana, LXXI, São Paulo, 1937.

(6). - Utilizamos a edição: C. CLUSIUS, Exoticorum libri decem..., ex officina Plantiniana Raphelengii, Leiden, 1605-1611.

(7). - C. CLUSIUS, o.c., p. 55, 364 e 371 .

(8). - C. CLUSIUS, o.c., p. 55. 
Middelburgo, Amsterdão, Francforte tinha seus informantes e correspondentes, muitas vêzes farmacêuticos ou cirurgiões, que lhe assinalavam qualquer novidade ou descoberta, ou então marinheiros e mercadores, que de suas viagens nas costas brasileiras traziam curiosidades. Assim havía Jacob Plateau de Tournai, que lhe mandava reproduções co'oridas e desenhos das coisas exóticas de seu "instructissimo museu" e que tinha obtido estas de Jesuítas, provàvelmente do pròprio Padre Fernão Cardim, então involuntàriamente de passagem nos Países-Baixos (9). Esta coleção, aliás, foi logo depois comprada por Charles de Croy, duque de Aaschot. Outros foram o cirurgião Joannes Langhe de Amsterdão, que, esteve no Brasil por volta de 1600, e o mercador Joannes van Uffele, que the mostrou em 1607 um caderninho com desenhos de plantas e animais feitos por êle mesmo na Bahia (10). Conclui-se daí que nos Países-Baixos um certo conhecimento da flora e fauna brasileira já era àmplamente divulgado antes da ocupação holandesa do Nordeste. Não era de estranhar visto a presença de muitos colecionadores de plantas entre os nobres da terra e os ricos mercadores. Sabemos que Clusius comunicava-se com um dôles, a mulher de Conrad Schetz, um dos proprietários do engenho dos Erasmos em São Vicente. Pudéssemos conhecer os jardins de seu castelo de Grobbendonck! A voga da botânica exótica nos meios mercantis e burgueses refletiu claramente na pintura da época. Mas a própria fixação do exótico na pintura significava um certo contraponto no empênho pelo desenvolvimento da botânica exótica, ao mesmo tempo que os PaísesBaixos Meridionais, consecutivamente sob dominação espanhola e austríaca, ao longo dos séculos XVII e XVIII se isolavam do movimento colonial e das viagens intercontinentais. A curta experiência da Companhia de Ostende com feitorias na China e na Bengália com alguns aportamentos no Brasil não parece ter ocasionado um nôvo incentivo. Assim, a botânica destas províncias não se aproveitou das grandes expedições científicas setecentistas e ficou à margem também da grande renovação linneana. Ela se fechou dentro de um utilitarismo estrito com o cultivo de plantas medicinais e com a implantação da cultura doravante tradicional do fumo e da batata. Esta última já aparece frequientemente no mercado de Bruges ao final do século XVII. Singularidade não sem mérito constituia a comercialização da cultura do abacaxí em estufas para as mesas da aristocracia .

$\mathrm{O}$ início do século XIX viu chegar profundas transformações na botânica exótica. Criaram-se então nas cidades de certa importância

(9). - C. ClUSIUS, o.c., p. 96 e 364 .

(10). - C. CLUSIUS, o.c., p. 42,46 e is. 
como Bruxelas, Antuérpia, Gand e outras, novos jardins botânicos. Fundaram-se sociedades como a Siciété Royale d'Agricu'ture et de Botanique de Gand em 1808. Estabeleceram-se vários comerciantes como importadores de flôres exóticas, tais como Jacob-Makoy em Liége, de Jonghe em Bruxelas, Papeleu em Wetteren, Van Geert em Antuérpia .

Quando procuramos explicar êste acontecimento, não podemos levar em conta qualquer participação da Bélgica na colonização, pois esta iniciaria só por volta de 1900 na África, nem tão pouco uma presença de belgas entre os famosos viajantes do período napoleônico. Se a obra de von Humboldt não ficou desconhecida na Bélgica, pouca ou nenhuma repercussão aí encontraram os relatos de viagens de naturalistas como Pohl ou de Saint-Hilaire ou as coleções brasileiras de Viena e Berlim. Antes tinha a botânica exótica sido despertada pela viagem do dr. von Siebold para o Japão, que trouxe plantas desconhecidas para o jardim de Leiden e da qual os belgas se aproveitaram graças a unificação com a Holanda, muito mais aberta para o ultramar, no Reino Unido dos Países-Baixos. Ou mais ainda pelo exemplo dos colecionadores inglêses, como o duque de Devonshire, que mandou seu jardineiro coletar novas variedades nos trópicos. Como em vários outros domínios, especialmente da industrialização, a Inglaterra passava então como a precursora, como o grande modêlo a ser imitado aos olhos da burguesia belga. Foi da Inglaterra que o horticultor Jacob-Makoy de Liège introduziu as primeiras orquídeas tropicais. Outros autores insistem, entretanto, nos esforços do horticultor Parmentier de Enghien, que teria antes obtido de Napoleão no meio do bloqueio continental o privilégio de importar da Ilha Britânica flôrēs exóticas para os jardins da imperatriz Joséphine e que após sua morte deixou uma coleção famosa de 2.000 orquídeas. Seja como for, flôres brasileiras começaram a aparecer nas coleções belgas nas primeiras décadas do século XIX. Ràpidamente, em poucos anos sobreveio um verdadeiro surto de amadorismo pela flora brasileira.

Primeiramente tentou-se estabelecer contactos diretos com o Brasil para ampliar as coleções e evitar a mediação inglêsa. Não é de estranhar que Antuérpia, pôrto que renascia então de uma letargia secular e de onde comerciantes belgas já tinham seguido para o Rio de Janeiro para estabelecer aí agências e casas de negócios, tomava nisto a dianteira. Assim, o jardim botânico desta cidade tinha plantado em 1823 uma Araucaria Brasiliensis recebida de seus correspondentes. Regularmente recebia pela sua intervenção caixas com flôres como a Acácia Speciosa e Begônias do Real Jardim do Rio de Janeiro, cujo diretor Frei Leandro do Sacramento se tornou famoso pela sua 
liberalidade (11). Outro aprovisionador generoso foi o príncipe Maximiliano de Wied-Neuwied, que mandou algumas Passifloras. Diretamente também do Rio o colecionador senador Heyndericx obteve a Amaryllis Reticulata.

Não devia demorar muito, num segundo passo, a tentação de organizar expedições e fazer viagens para o Brasil. A primeira iniciativa coube aos irmãos Philippe et François Vandermaelen, que dirigiam, numa feliz combinação de curiosidade científica e de espírito comercial, em Molenbeek, subúrbio de Bruxelas, um instituto particular dedicado às ciências, desde a arqueologia e a cartografia até a botânica, com cursos gratuitos, mapoteca, museu de história natural e jardim botânico (12). Eles é que mandaram em 1832 seu taxidermista Deyrolle e jardineiro Crabbe para uma viagem de dezesseis meses pelo Brasil. Desconhecemos ainda seu roteiro, mas sabemos que na sua volta trouxeram uma rica coleção de flôres e expuseram orquídeas no salão da Société de Flore de Bruxelas em 1834.

O segundo a arriscar a aventura botânica foi Louis van Houtte, originário de Ipres (* 1810), com formação de estudos comerciais em Paris e Clermont-Ferrand (13). Participou com entusiasmo na revolução belga de 1830 , mas não chegou a emburguesar-se como funcionário do nôvo Estado. Antes abriu uma loja de flôres e sementes em Bruxelas e à base de conhecimentos botânicos adquiridos no Jardim Botânico desta cidade, fundou em 1833 uma revista de divulgação botânica. Para esquecer a morte prematura da espôsa e com o apôio do próprio rei Leopoldo e do rico colecionador Parthon de Von, de Wilrijk, decidiu-se para uma viagem ao Brasil a fim de recolher flôres. Ainda jovem, com apenas 24 anos, embarcou em janeiro de 1834 para o Rio de Janeiro, levando material apropriado, uma espécie de estufas em miniatura.

Durante sua estadia, que ultrapassou o ano, van Houtte teria percorrido as províncias de Rio de Janeiro, Minas Gerais, Mato Grosso, Goiás, São Paulo com o Paraná. No relato desta viagem, que êle publicou dez anos depois, instigado pelo exemplo e pelo êxito do livro de Gardner, apenas descreve sua chegada ao Rio de Janeiro e uma excursão até a Serra dos Orgãos, passando por Piedade, Magé,

(11). - A. MARChANT, Dom João's Botanical Garden, in The Hispanic American Historical Review, XLI, 1961, p. 259-274.

(12). - R. GEORLETTE, Les chasseurs de plantes, Quelques collecteurs belges, in Annales de Gembloux, 1951, p. 198-224; L'orchidée en Belgique, catálogo de exposição, redigido por J. BALIS e A. LAWALRÉE, Bruxelas, 1961.

(13). - A. BUYSSENS, Louis van Houtte, Notice biographique, Gand, 1913. 


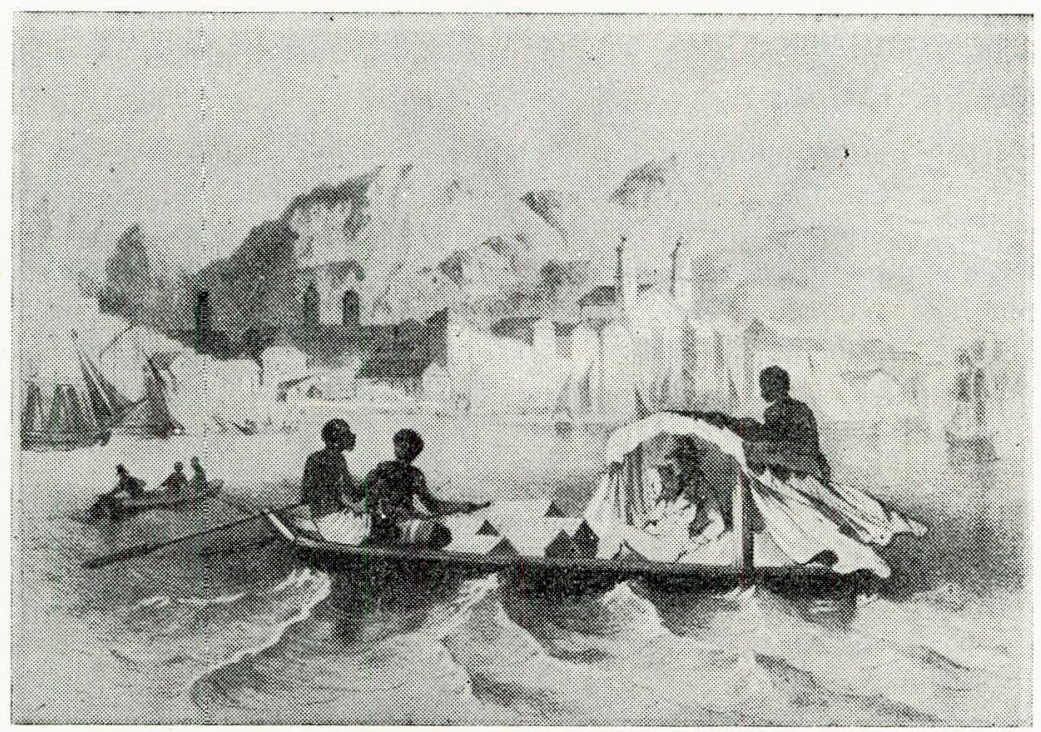

Fig. 1. - Van Houtte desembarcando no Rio de Janeiro.

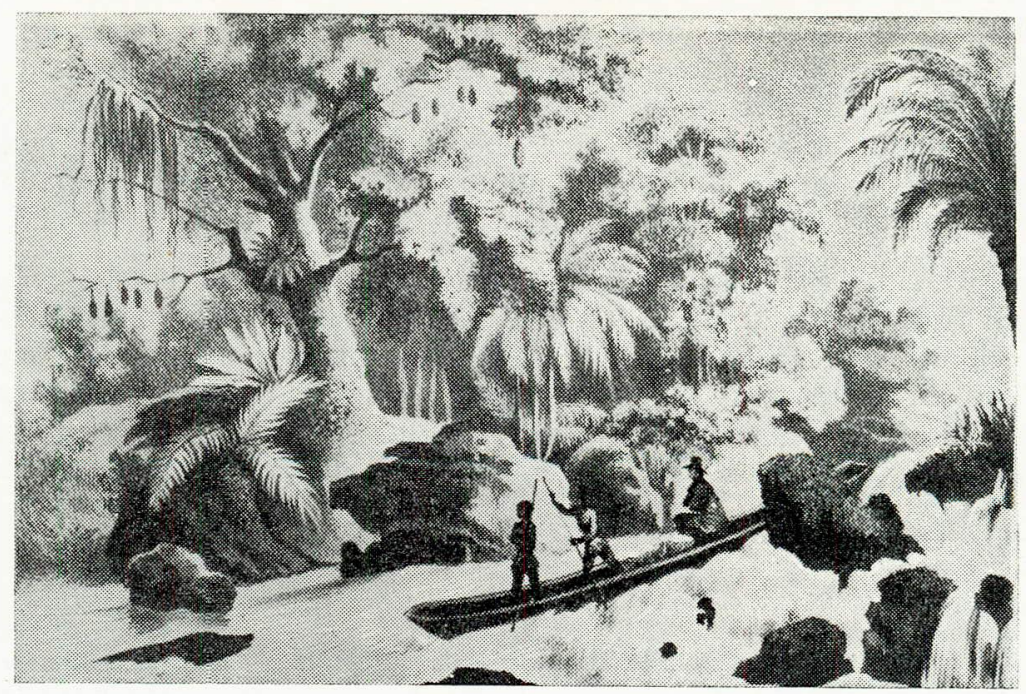

Fig. 2. - Viagem de Van Houtte numa canoa. 


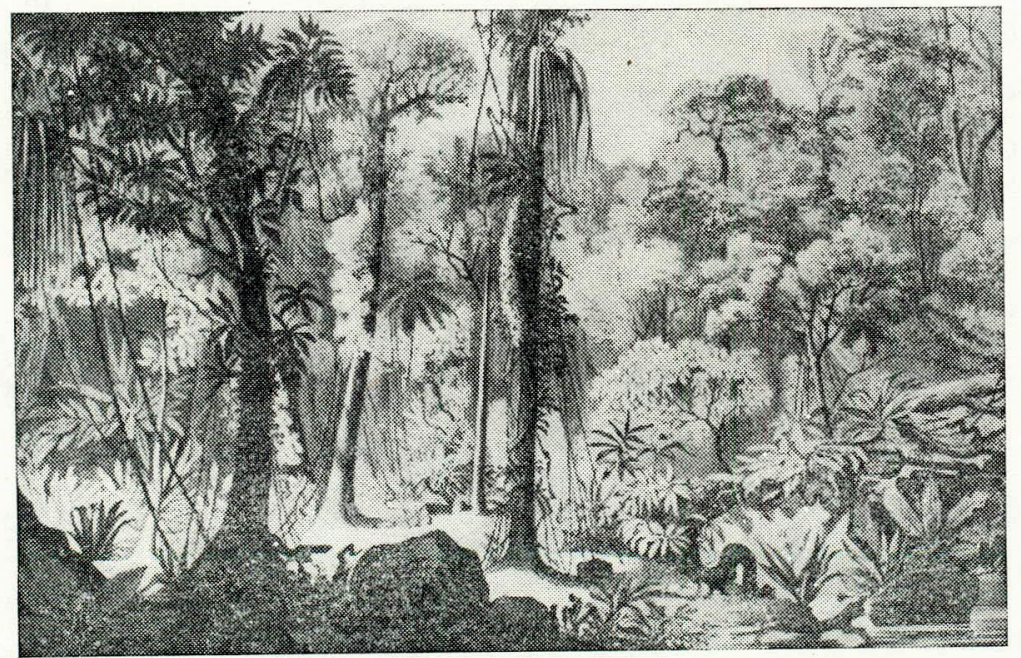

Fig. 3. - Floresta virgem no Brasil. 


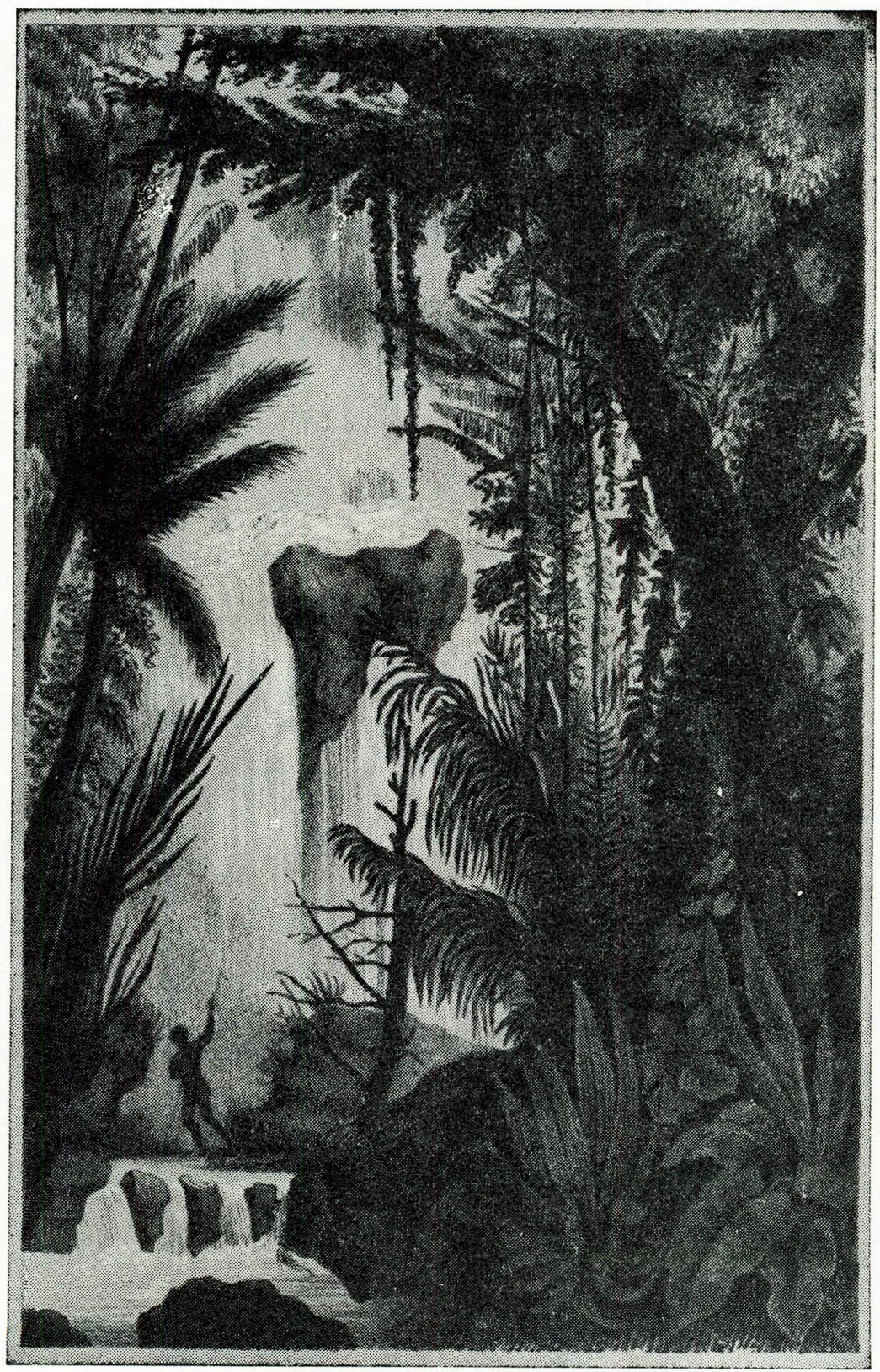

Fig. 4. - Cascata numa floresta virgem. 


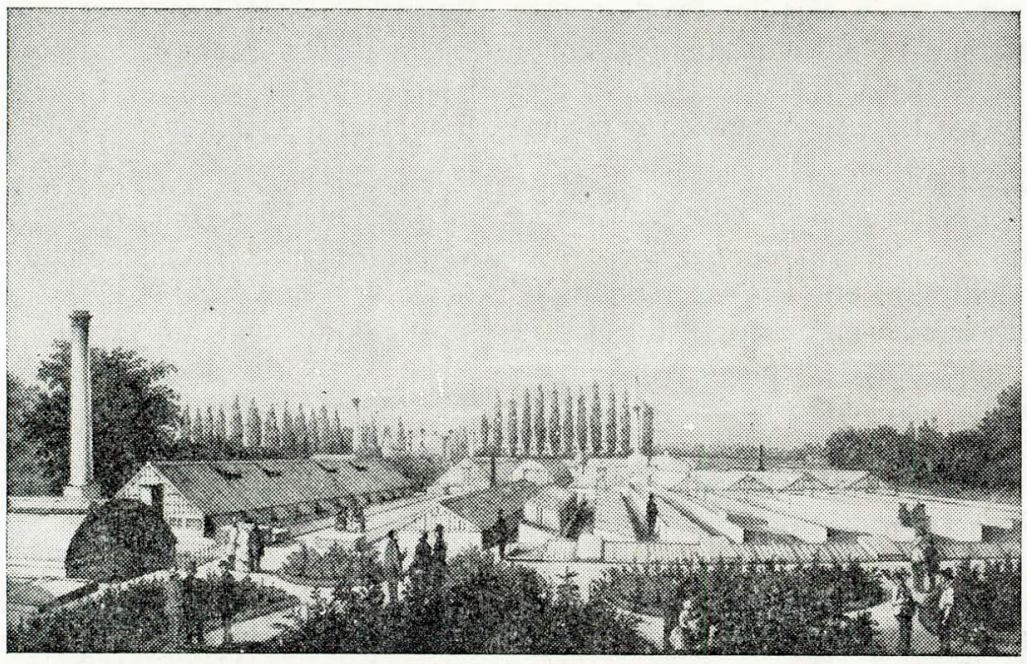

Fig. 5. - Vista da emprêsa Van Houtte em Gentbrugge.

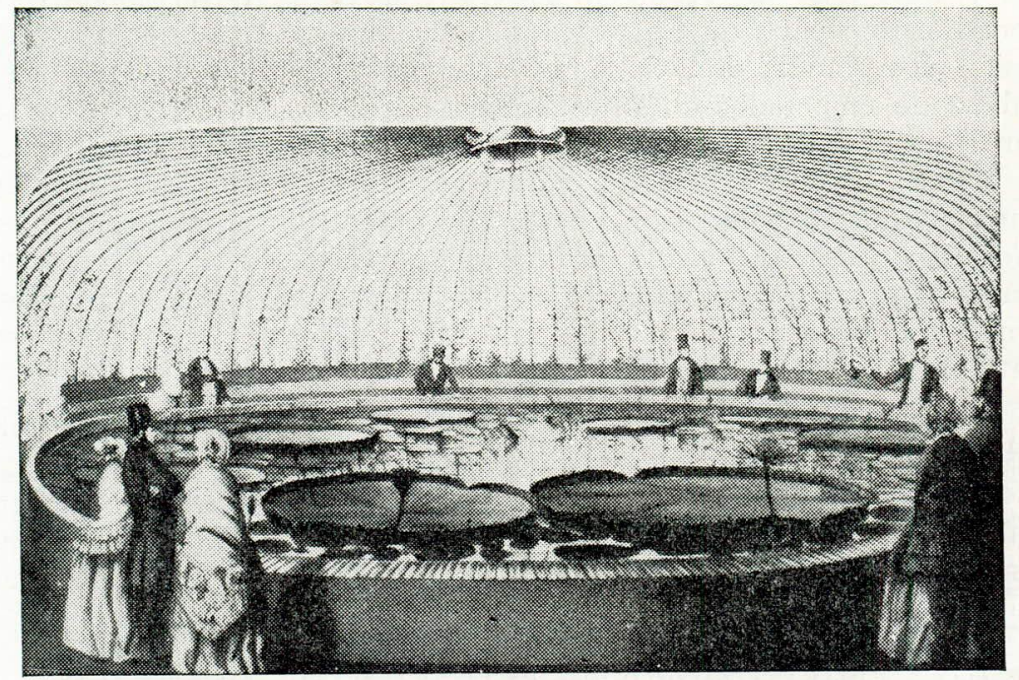

Fig. 6. - A estufa da Victoria Regis. 
Freichal até a famosa fazenda do inglês March (14). Pouco ou nada veio contribuir para a literatura dos viajantes: descrições de um rancho e uma venda, dos hábitos de comer e de danças de negros. $O$ especialista em botânica e zoologia encontrará aí alguns dados sôbre localização de várias espécies. No resto a típica verbiagem romântica sôbre a floresta virgem, a pequenez do homem e a majestuosidade da natureza.

$\mathrm{Na}$ viagem de volta ainda visitou a Guatemala e Honduras. Em Bruxelas logo assumiu a direção do Jardim Botânico, mas como não encontrasse entre seus colaboradores o entusiasmo esperado, dicidiu fundar uma emprêsa de floricultura e horticultura com fins científicos e comerciais. Escolheu para tal a localidade de Gentbrugge, perto de Gand, que então começou a destacar-se como um dos maiores centros florísticos do mundo e contava em 1836 com nada menos de 206 estufas. Do Brasil van Houtte trazia novidades preciosas como o Dendrobium Squalens, a Gessneria Houttei ou o Cereus Gongo-soccensis, descoberto num arraial perto de Sabará (15). Sua grande especialidade foram as Amaryllis, chamadas de orgueilleuses filles du Brésil, e as Bertolonias, que êle aperfeiçoou, cruzou, hibridou e popularizou por tôda a Europa.

Em poucos anos suas estufas se tornaram tã் famosas que podiam sofrer a comparação com os Kew Gardens perto de Londres ou com a casa Veitch de Chelsea e que ficaram ponto obrigatório nas visitas dos grandes dêste mundo, da rainha Vitória, do rei de Portugal ou do emperador do Brasil, que outorgou a Ordem da Rosa a van Houtte. Particular admiração causava sua Victoria Regis, exposta numa estufa especial. Seus êxitos comerciais permitiram a edição em colaboração com os mais famosos botânicos da época de uma Flore des Serres et Jardins de l'Europe em 23 volumes, que descreveram para um largo público europeu centenas de flôres brasileiras, e mais a criação de uma escola de horticultura dentro de sua emprêsa, patrocinada pelo Estado.

Van Houtte não voltou a viajar, mas mantinha informantes e correspondentes em vários lugares do Brasil e por tôda a América, como o capitão Capanema, a quem deveu a Otacanthus Coerulens, e Carl Pabst no Brasil, como Hermann Kegel nas Guianas, Papeleu na Guatemala, Warscewiez na Venezuela. Assim teve êle na Europa as

(14). - L. VAN HOUTTE, Courte excursion dans les montagnes des Orgues et dans les forêts vierges du Brésil, in Flore des Serres et des Jardins de l'Europe, III, 1847 , p. 282 e 302 e IV, 1848, p. 333.

(15). - L. VAN HOUTTE, Notice sur quelques plantes nouvelles, cultivées au Jardin Botanique de Bruxelles, in L'Horticulteur Belge, III, 1836, p. 247-251. 
primícias da Cocos Weddeliana, da Washingtoniana Robusta e da Phoenicophozium. Sechellarum. Nunca se cansou de atualizar-se e quando morreu em 1876 deixou uma emprêsa florística, talvez sem grande futuro comercial, mas da mais séria reputação científica na Europa .

Poucos meses depois do embarque de van Houtte seu exemplo foi seguido por Jean-Jules Linden, nascido em 1817 no Luxemburgo, mas belga por opção de nacionalidade. Estudava ciências na nova Universidade de Bruxelas quando se deixou animar pelos irmãos Vandermaelen e foi liderar, sob os auspícios do govêrno belga, uma expedição científica nas províncias do Rio de Janeiro, Minas Gerais, Mato Grosso, Goiás, Espírito Santo e São Paulo. Na sua companhia encontravam-se o desenhista Nicolas Funck, o botânica e zoólogo Auguste Ghiesbrecht e um certo Jaquet. De volta em 1837, após mais de um ano de excursões, organizaram em Bruxelas uma exposição com o material obtido, no qual figuravam a Gessneria Cinnabarina, a Abelia Floribunda e a Chamaerops Stauracanthe.

Linden chefiou ainda duas outras importantes expedições, uma pelo o México, a Guatemala e Cuba e outra pela Colômbia e pela Venezuela. Finalmente seguiu uma carreira semelhante a aquêla de van Houtte. Tornou-se diretor do Jardim Botânico de Bruxelas em 1845 e fundou também sua emprêsa particular, localizada primeiramente na capital, posteriormente em Gand. Lá foi êle o iniciador na Europa da criação de orquídeas em estufas frias, razão pela qual foi chamado de pai das orquídeas. Ao mesmo tempo que editou uma famosa Iconographie des orchidées, não se cansava de completar suas coleções com a colaboração de vários herborizadores belgas e estrangeiros (16). Citemos entre êstes Libon e Claes, dos quais tratamos logo, Edouard André no alto Amazonas, Marius Porte de 1854 a 1859 na Bahia, em Alagoas e na Amazônia, Gustave Wallis, de 1860 a 1862 no Rio Negro, que the expediu a Passiflora Fulgens, a Asterostigma Zebrina, a Gustavia Brasiliensis.

Uma quarta expedição belga para o Brasil partiu em 1841, dirigida pelo chevalier de Claussen, que talvez possa ser identificado com Pedro Clausen, dinamarquês e amigo de Lund, proprietário de uma fazenda em Porteirinhas, mas radicado nos anos de $1840 \mathrm{em}$ Bruxelas (17). Para lá trouxe uma coleção de Buritis, de Luxemburgia e uma Hypocrita Scabrida. Seu companheiro de viagem foi

(16). - J. LINDEN, L. LINDEN e E. RIGODAS, Lindenia, Iconographie des Orchidées, Gand, 1885-1903, 17 volumes in-folio.

(17). - C. CHRISTENSEN,' Den Danske Botaniks Historie, Copenhagen, 1924-1926, I, p. 247 e III, p. 209-210. 
um jovem aprendiz-jardineiro de Jacob-Makoy de Liège, Joseph Libon, nascido em 1821 em Verviers. Este, mal tendo regressado de sua primeira viagem, já partiu uma segunda vez em 1846 para o Brasil, desta vez a serviço do horticultor de Jonghe de Bruxelas. e herborizou no Corcovado, em Minas Gerais e perto de Itú e Ipanema (18). Decididamente apaixonado pela flora brasileira voltou outra vez em 1859 com encomendas do horticultor Linden e percorreu sobretudo os campos de Santa Catarina e a costa de Santos ao Rio de Janeiro. A Libon deve-șe a introdução da Pionandra Fragrans, da Libonia Floribunda, da Franciscea Lindeniana, da Rhopaia Aurea e da Aphelandra Libonia. Vítima de seu zêlo herborizador faleceu de febres malignas em Insaima em 1861.

Santa Catarina por esta época já tinha sido percorrida por dois outros naturalistas belgas, ligados às colônias belgas de lá: François de Vos e de Rijcke. O primeiro mandou de 1845 a 1848 a Laelia Purpurata, a Dipladenia Nobi.is, a Cattleya Leopoldi, a Codonanthe Devosiana, a Costus Verschaffeltianus, a Brassavola Fragrans e a Peirescia Undulata para os horticultores Verschaffelt de Gand (19). Esta emprêsa, que posteriormente passou para as mãos de Linden, era sem dúvida a terceira em importância e mantinha vários coletores. No Brasil contavam com Charles Pinel, naturalista diletante residente em Morro Queimado por volta de 1850-1856, que apresentava memórias sôbre a constituição geognóstica e a vegetação da sua região à Academia belga de Ciências, por sinal pouco apreciadas, e que lhes mandou a Warrea Digitata, a Burlingtoneana Venusta e a Miltonia Cuneata (20). Entre seus fornecedores havia ainda Monsieur Baraquin, um francês residente no Pará, que de 1859 a 1863 lhes despachou uma Achyrantes Verschaffelti, uma Passiflora Baraquiniana, uma Gymnostachium Verschaffelti e várias espécies de Caladium.

Não pudemos identificar um L. A. Picard que pelos anos 1855-1858 percorreu o sul do Brasil (21).

O último destes naturalistas-horticultores que coletou no Brasil foi Florent Claes (* 1869), primeiramente a cargo de Linden, depois por conta própria. A partir de 1890 atravessou 12 vêzes o Atlântico rumo ao Brasil e à Colômbia. Sua grande descoberta, em Pernambu-

(18). - E. MORREN, Notice biographique sur Joseph Libon, in La Belgique Horticole, XIV, 1864, p. 14-15 e XV, 1865, p. 46-47.

(19). - CH. MORREN, Annales de la Société Royale d'Agriculture et Botanique de Gand, III, 1847, p. 332 e V, 1849, p. 174 e 210.

(20). - Bulletins de l'Académie Royale des Sciences, des Lettres et des BeauxArts de Belgique, XIX, 2, 1852, p. 481-488.

(21). - L. LINDEN, A. COGNIAUX e G. GRIGNAN, Les orchidées exotiques et leur culture en Europe, Bruxelas e Paris, 1894, p. 119. 
co, foi a Cattleya Labiata Lindley. Mas as pesquisas de Claes eram o epílogo já de tôda uma época.

A partir dos anos de 1870 notou-se uma reduç ̃o senão uma crise neste ardor herborizador pela flora brasileira. Vários acontecimentos e elementos podem explicar isto. Alguns países - e deveria examinar-se se o Brasil se encontra entre êles - proibiram doravante a exportação de plantas exóticas para estimular uma horticultura nacional (22). De outro lado esboçou-se nos próprios países europeus uma certa reação de cunho nacionalista contra o exotismo botânico, que se enfatuou agora mais da flora nativa pobre e humilde. Quem continuava entretanto fascinado pela botânica itropical, voltava-se agora mais para a África e isto era tanto mais fácil que os belgas começaram a interessar-se pela colonização do Congo por Leopoldo II. Finalmente, com a saturação na constituição de novas coleções e na introdução de novas espécies o interêsse restante se orientou mais para plantas híbridas e bastardas. Em conseqüência, as grandes emprêsas hortícolas de Gand e outras cidades belgas diminuiram ou terminaram a obra de herborização no Brasil e orientaram-se cada vez mais para a produç̃̃o em massa de flôres tropicais, especialmente certos tipos de orquídeas. Estas evoluiram de objeto de coleção sofisticada para patente de status social. De agora em diante a orquídea brasileira se encontraria no buquê de casamento de tôda noiva distinta ou no túmulo do nôvo-rico. Esta comercialização em escala industrial foi em parte possibilitada pela invenção e pelo aprimoramento de um processo de cultivar orquídeas a partir de sementes na emprêsa de Charles Vuylsteke. Assim mesmo o inglês Frederic Sander, denominado de Orchid King, que tinha estabelecido em 1894 perto de Bruges uma enorme emprêsa, importava anualmente de 100.000 à 200.000 orquídeas da América do Sul.

O desaparecimento da iniciativa particular e hortíco'a belga na herborização da flora brasileira não significava necessàriamente que esta se afastasse do horizonte da botânica belga. O interêsse oficial e mais genuìnamente científico do Estado e de organismos universitários revezou a partir de 1870 o setor privado deficiente. O Jardim Botânico de Bruxelas, em dificuldades financeiras, foi comprado pelo Estado e dotado com os herbários brasileiros de Martius. Seu diretor, Crépin, conseguiu interessar Elie Marchal e sobretudo Alfred Cogniaux na colaboração e continuação da Flora brasiliensis do ilustre botânico alemão. Cogniaux se destacou como um dos maiores sistematizadores de orquídeas e mantinha a respeito correspondência

(22). - J. BALIS, Hortus Belgicus, catalogo da exposição na Biblioteca Alberto I, Bruxelas, 1962, p. 66-67. 
com Barbosa Rodrigues, que aliás procurou editar em Bruxelas várias de suas obras (23). Organizaram-se umas expedições oficiais com maiores pretensões científicas. Com o biólogo Van Beneden ia em 1872 o botânico Camille Van Volxem o qual coletou no Rio de Janeiro, em Minas Gerais e na Serra do Mar em São Paulo (24). De maior vulto foi a expedição de Jean Massart e de Raymond Bouillenne, que em 1922-1923 operaram nos passeios públicos e nos terrenos baldios do Rio de Janeiro, na Bahia, no Pará e na Amazônia (25). Pouca ou nenhuma repercussão tiveram todos êstes emp̣?enhos científicos na floricultura de Gand.

Destaca-se portanto na história da botânica belga um período, que vai de 1800 a 1870 mais ou menos, bem caracterizado por laboriosos e extraordinários esforços de herborização belga da flora brasileira simultâneamente com grande aceitação da mesma num público seleto e notáveis êxitos comerciais. Como poderíamos relacionar êste fenômeno com a história social da época? De fato, o século XIX viu um espetacular desenvolvimento da floricultura e horticultura exótica, bem visível pelo menos na Bélgica. Cada cidade de certa importância contava dezenas de colecionadores, em número suficiente para poder organizar salóes e concursos anuais, como em Bruxelas, Bruges, Lovaina, Antuérpia, Tournai, Malinas, Namur, Gand e Liége (26). Os mais importantes emulavam-se em certames internacionais e junto com as primeiras exposições mundiais surgiram as Floralies, em 1864 em Amsterdão e em 1866 em Londres (27). Linden, por exemplo, ganhou em Amsterdão várias medalhas de ouro com uma Dioscorea Anoechtochilus da Amazônia e com uma Franciscea Lindeniana da Santa Catarina. As Floralies de Gand se tornaram as mais famosas e ainda hoje se organizam cada qüinquiênio. Esse interêsse público suscitou um vasto movimento editorial: comentários indispensáveis nos jornais, catálogos preciosos de cada coleção,

(23). - A. GOGNIAUX, Notes sur les orchidées $d u$ Brésil et des régions voisines, in Bulletin de la Société Royale de Botanique de Belgique, XLIII, 1906, p. 266-356; J. BARBOSA RODRIGUES, Les noces des palmiers, Bruxelles, 1903.

(24). - E. VAN BENEDEN, Rapport sommaire sur les résultats d'un voyage au Brésil et à la Plata, in Bulletin de l'Académie Royale des Sciences, des Lèttres et des Beaux-Arts de Belgique, 2e série, XXXV, 1873, p. 775-792.

(25). - J. MASSART, R. BOUILLENNE e outros, Une mission biologique belge au Brésil (Août 1922-Mai 1923), Bruxelas, 1925-1930, 2 tomos.

(26). - Entre os mais famosos colecionadores belgas mencionamos Parthon de Von, o barão Osy, o duque de Arenberg, o conde de Kerchove de Denterghem, Leg1 elle-d'Hanis, A. Brys, Cannart d'Hamale, Heynderickx e o próprio rei Leopoldo I em Laeken.

(27). - E. MORREN, Plantes de Serres, Rapports du iury international, Exposition universelle de 1867, Paris, 1867. 
e várias revistas especializadas como L'Illustration horticole. Paralelamente desenvolveu-se a especialidade artística de uma custosa e luxuosa ilustração botânica. Van Houtte tinh ha seu atelier especial e um de seus artistas, Louis Stroobant, que trabalhava também para Verschaffelt, fêz dezenas de litografias de plantas, árvores e paisagens, talvez não sempre muito originais, mas bem típicas e divulgadas de uma imagem fácil de um Brasil exótico (28).

Os prêços astronômicos que se chegou a pagar por certas espécimes, como por exemplo os 30.000 francos pagos por Devonshire para uma Palaenopsis Amabilis em 1837, podem levar a crer que nos encontramos aqui diante de um fenômeno semelhante à tulipomania, que assolava a burguesia holandesa pelos anos 1640, com até cotação na bôlsa, excrescência específica do capitalismo comercial estéril. Sem dúvida a orquideomania do século XIX está ligada à enorme capitalização e à especulação da classe burguesa da época, que existia então numerosa na Bélgica e incluia muitos nobres. Deve-se entretanto salientar que a procura e o cultivo de flôres exóticas encontrava então uma funçã̃o mais puramente econômica pela rápida comercialização e extensão da floricultura e como política de prestígio e de publicidade das grandes emprêsas hortícolas. Muitos colecionadores autofinanciavam sua coleção pela venda de certas espécies a 25 ou 50 francos ou pelo intercâmbio. Os floricultores mantinham orquidários para atrair visitantes e poder vender-lhes flôres mais populares e menos custosas.

Mesmo se do ponto de vista econômico esta herborização e esta colecionação na flora tropical apresenta um aspecto assaz gratuito ou até anti-econômico, em franca oposição com as pesquisas botânicas dos séculos XVI e XVII bem interessadas na procura de drogas e medicinas, elas se justificavam por uma nítida e inegável motivação de ordem social e em última análise também econômica. A botânica, antes quase um privilégio dos reis, do alto clero e das abadias, passou no século XIX por uma democratização e laicização e teve importante papel na promoção, integração e afirmação da classe burguesa nos meios dominantes. Típica neste sentido foi a decisão da Revolução Francesa de juntar em jardins públicos as coleções abandonadas dos conventos e dos émigrés e daí procederam a maioria dos jardins botânicos nas províncias belgas. A preferência da flor sôbre os arbustos num jardim arquitetado refletia também a vitória do individualismo político sôbre a ideia monárquica e absolutista. As coleções botâ-

(28). - L'Illustration horticole, II, 1855, p. 1, III, 1856, p. 105 e V, 1858, p. 54 . 
nicas, como mais tarde aquelas de pinturas, projetavam o nome de seus proprietários. Nas exposições e nos concursos estes nôvos-ricos, amparados por títulos nobiliários recentes, podiam mais fàcilmente frequientar a alta e velha aristocracia desde príncipes russos até rainhas desiludidas e duquesas emancinadas. As flôres constituiam o vínculo de uma espécie de maçonaria orquideófila. Nas estufas, as vêzes já iluminadas à gaz e verdadeiras jóias da arquitetura, é que de preferência organizavam suas reuniões sociais e concertos. Ainda hoje os reis dos belgas recebem nas estufas reais de Laeken. Verschaffelt organizava até lotreias com flôs. Uma nova variedade florística podia tornar-se o veículo preferido para imortalização de seu nome, ao passo que antes flôres levavam nomes de santos ou populares. A arte da conversação fútil e esnobe encontrava aí um assunto sem perigo. Finalmente, pode também ver-se como um meio de distanciamento da pequena classe média e dos operários, que deviam contentar-se com flôres populares, com jardinzinhos ou com os squares das cidades.

Além disso, a botanomania se enquadrava bem na cultura da época. Ela permitia uma fácil e ostentativa adesão ao cientificismo reinante. As orquídeas plantavam claramente o problema da origem das espécies e do mecanismo de sua evolução como Darwin o estava estudando. Na vida das plantas o idealismo burguês se espelhava em tôda sua complacência, como suas crenças no evolucionismo, na luta pela vida, na sobrevivência e no aperfeiçoamento das melhores espécies, e se firmava no seu carreirismo e na hierarquia social estabelecida. A variedade de flôres de todos os continentes reunidas nas suas estufas convencia lest bourgeois conquérants de seu domínio do mundo. Os catálogos propagandísticos da flora exótica não recuavam até de insistir no valor moral da botanofilia. Admirar flôres como ouvir música eram proclamadas capacidades exclusivas do homem. Aí podia-se encontrar além da divisão política e do espírito partidário a pureza e a tranqüilidade indispensáveis. Aí oferecia-se um refúgio à mão para desilusões, como para van Houtte após a morte da espôsa, e para êste pessimismo burguês, outra face de seu idealismo. A estufa tinha a porta sempre aberta para o exotismo de fuga e de fácil consôlo. Não estranhemos portanto a exaltação exuberante que encontramos a cada passo nos escritos de naturalistas improvisados e nas publicações de horticultores zelosos. Van Houtte na descrição de suas excursões com dificuldade encontrava palavras suficientes para cantar a impressão da floresta virgem, dos enormes fetos, das grinaldas de fúchsias. O admirador de uma flor numa exposição se interrogava ingênuamente quanto sangue humano a procura desta tinha custado. Expressões como "martirológio dos botânicos" ou "panteão da botânica", então freqüentemente usadas, nos fazem hoje sorrir. 
Há ainda que apontar o impacto desta botanomania nas artes. A flora exótica influiu profundamente nas criações dos prerafaelitas e dos impressionistas ou de pintores isolados como Odilon Redon. Tôda a art nouveau nas jóias, nos móveis, nas artes gráficas leva sua marca digital. Não é por certo fortuito se na Bélgica, tão empolgada pela flora tropical, surgissem artistas como Victor Horta ou Vande Velde. O colorismo tão particular, tão inhabitual para Flandres, e com tantas novidades de um James Ensor procede não só de seu contacto diário com conchas exóticas mas também de seus conhecimentos da flora tropical. Maior ainda foi sua repercussão na arquitetura, onde a construção de estufas com vidro e ferro inspirou o famoso Crystall Palace de 1851 em Londres e provocou uma importante renovação arquitetônica, bem mais original que o estilo pompier do Segundo Império francês. Outrosim, a flora tropical criou tôda uma mistificação literária. O tema merece ser arrolado nas obras da época. Para alguns as orquídeas eram as verdadeiras fleurs du mal, filles aimées de la fièvre, enfants de l'air corrompu (29). Outros celebravam, reanimando uma velha tradição popular, suas fôrças e seus mistérios afrodisíacos. Ou então a apreciação de Maurice Maeterlinck:

"C'est parmi les Orchidées que nous trouverons les manifestations les plus parfaites et les plus harmonieuses de l'intelligennce végétale",

que lhes consagrou belas páginas $(30)$.

Afinal as viagens de uma dezena de naturalistas belgas pelo Brasil significavam bem mais que uma herborização e um simples enriquecimento da botânica. Deram origem a uma nova atividade econômica na região de Gand, que ainda hoje ocupa centenas de homens e rende apreciáveis divisas. Alicerçaram todo um comportamento social. Ofereceram um antídoto para a feiúra e banalidade do século XIX. Propagaram uma certa imagem do Brasil, que até há pouco nimbava o país com flôres. Encontramos assim o Brasil num canto insuspeito de terras flamengas.

(29). - J. MICHELET, L'Oiseau, Paris, 1856, p. 82-83.

(30). - M. MAETERLINCK, L'intelligence des fleurs, in Insectes et fleurs, Paris, 1954, p. 496-509. 